\title{
Narrativas de vida de pacientes oncológicos sob cuidados paliativos: o olhar das peças poéticas
}

\author{
Life narratives of cancer patients under palliative care: the look of poetic pieces \\ Narrativas de vida de pacientes con cáncer en cuidados paliativos: la mirada de las piezas poéticas
}

Recebido: 26/08/2021 | Revisado: 01/09/2021 | Aceito: 08/09/2021 | Publicado: 11/09/2021

José Carlos Malafaia Ferreira

ORCID: https://orcid.org/0000-0002-7626-768X Universidade Municipal de São Caetano do Sul, Brasil

E-mail: jose.ferreira@online.uscs.edu.br

Rosamaria Rodrigues Garcia

ORCID: https://orcid.org/0000-0001-9454-6810 Universidade Municipal de São Caetano do Sul, Brasil

E-mail: rosamaria.garcia@online.uscs.edu.br

\begin{abstract}
Resumo
Introdução: dor total em cuidados paliativos implica atenção às dimensões biopsicossocial e espiritual de cada um. A dor de alguém com câncer transcende sua dor física. Conhecer alguém além da sua moléstia, iluminando suas subjetividades, pode tonificar condutas mais humanizadas e favorecer uma relação médico-paciente que se beneficiará com o aguçamento da empatia pelo médico. Objetivo: apresentar peças poéticas sobre os aspectos mais valiosos da vida de pacientes oncológicos sob cuidados paliativos, baseadas em narrativas de vida. Método: estudo qualitativo, prospectivo, exploratório, pautado na metodologia das narrativas orais de histórias de vida de pacientes oncológicos, matriculados no ambulatório de Cuidados Paliativos do Centro Oncológico, do município de São Caetano do Sul. O ambulatório foi renomeado para Anamnese Ampliada, sendo coletadas duas entrevistas: a primeira, onde o entrevistado foi instigado a produzir um relato de vida desde a infância e até antes dos sintomas da doença. Na segunda, o paciente foi apresentado a uma obra artística consagrada e discorreu sobre o efeito que a obra lhe causou. Resultados: as narrativas possibilitaram a compreensão de aspectos inacessíveis à avaliação tradicional, aproximando o médico e o paciente, promovendo abordagem integral e empática proposta pelos princípios dos cuidados paliativos. Considerações finais: as peças poéticas podem fomentar o olhar de empatia dos profissionais que tratam do paciente oncológico em paliação, bem como do alunado, que inicia o contato com a prática de uma medicina humanizada.
\end{abstract}

Palavras-chave: Cuidados paliativos; Medicina narrativa; Humanização da assistência; Ensino; Conhecimentos, atitudes e prática em saúde.

\begin{abstract}
Introduction: Total pain in palliative care implies attention to the biopsychosocial and spiritual dimensions of each person. The pain of someone with incurable cancer transcends their physical pain. Getting to know a person beyond their illness, illuminating their subjectivities, can tone up more humanized behaviors and a favor of a doctor-patient relationship that will benefit from the enhancement of empathy on the part of the doctor. Objective: to present poetic pieces about the most valuable aspects of the life of cancer patients under palliative care, based on life narratives. Method: this is a qualitative, prospective, exploratory study, based on the methodology of oral narratives of life histories of cancer patients enrolled in the Palliative Care clinic of the Oncology Center in the city of São Caetano do Sul. The clinic was renamed Extended Anamnesis, and two interviews were collected: the first, where the respondent was instigated to produce a life report from childhood until before the symptoms of the disease. In the second, the patient was introduced to a renowned artistic work and discussed the effect that the work had on him. Results: the narratives made it possible to understand aspects that are inaccessible to traditional assessment, bringing the doctor and the patient closer together, promoting a comprehensive and empathetic approach proposed by the principles of palliative care. Conclusion: inspired poetic pieces can foster the empathetic look of professionals who treat cancer patients undergoing palliation, as well as students, who initiate contact with the practice of humanized medicine.

Keywords: Palliative care; Narrative medicine; Humanization of assistance; Teaching; Health knowledge, attitudes, practice.

\section{Resumen}

Introdución: Dolor total en cuidados paliativos implica la atención a las dimensiones biopsicosociales y espirituales de cada persona. El dolor de alguien con cáncer trasciende su dolor físico. Conocer a una persona más allá de su enfermedad, iluminando sus subjetividades, puede tonificar comportamientos más humanizados y favorecer una relación médico-paciente beneficiada por la potenciación de la empatía por el médico. Meta: Presentar piezas poéticas
\end{abstract}


sobre los aspectos más valiosos de la vida de los pacientes oncológicos en cuidados paliativos, a partir de narrativas de vida. Método: se trata de un estudio cualitativo, prospectivo, exploratorio, basado en la metodología de narrativas orales de historias de vida de pacientes con cáncer inscritos en la clínica de Cuidados Paliativos del Centro de Oncología del la ciudad de São Caetano do Sul. La clínica pasó a denominarse Anamnesis Extendida, y se recogieron dos entrevistas: la primera, donde se instigó al entrevistado a realizar un relato de vida desde la infancia hasta antes de los síntomas de la enfermedad. En la segunda, se presentó al paciente una obra artística de renombre y se habló del efecto que la obra tuvo en él. Resultados: las narrativas permitieron comprender aspectos inaccesibles a la valoración tradicional, acercando al médico y al paciente, promoviendo un abordaje integral y empático propuesto por los principios de los cuidados paliativos. Consideraciones finales: las piezas poéticas buscan fomentar la mirada empática de los profesionales que tratan a los pacientes oncológicos en paliación, así como de los estudiantes, que inician el contacto con la práctica de la medicina humanizada.

Palabras clave: Cuidados paliativos; Medicina narrativa; Humanización de la atención; Enseñanza; Conocimientos, actitudes y práctica en salud.

\section{Introdução}

São vários os dados a serem observados quanto aos princípios do tratamento de um paciente com câncer. Entre tantos, estão os que dizem respeito à doença em si, que denotam sua extensão, prognóstico, os que envolvem tratamentos propostos, e com isso a participação de todos que cuidam do paciente, e com ele se relacionam (Spence \& Johnston, 2001).

Cuidados Paliativos, segundo a Organização Mundial da Saúde [OMS] (2002), consistem na assistência ofertada por uma equipe multidisciplinar, que tem por objetivo a melhoria da qualidade de vida do paciente e de seus familiares que se encontram diante de uma doença que ameace a vida, por meio da prevenção e do alívio do sofrimento, da identificação precoce, avaliação impecável e tratamento de dor e demais sintomas físicos, sociais, psicológicos e espirituais.

Paliar confunde-se, mesmo entre médicos, com o "não há mais nada a se fazer", ou, "não tem mais tratamento". São recorrentes as tentativas de manter vivo o doente com câncer incurável com terapêuticas e procedimentos que só pioram a sua qualidade de vida.

O especialista em Cuidados Paliativos quase sempre recebe pacientes e familiares, sem que se tenha essa fala inicial sobre a irreversibilidade da doença, o que aumenta mais suas angústias. Um corpo bastante fragilizado, por vezes, caquético, inapetente, com ingesta quase inexistente é quadro comum na progressão do câncer. Um ser humano que vive seus momentos derradeiros e ninguém comenta sobre isso, nem seu médico; pode morrer sem uma informação que é determinante para decisões e vontades que gostaria de ter colocadas (ANCP, 2009).

E sim, é possível falar desse tempo final. É necessário. Claro, há maneiras de se comunicar notícias ruins, e isso deve ser um exercício contínuo para quem assiste pacientes com câncer. Não há como evitar. A doença avançada, por vezes revela um luto em vida, uma realidade difícil de lidar, que muitas vezes se tenta modificar com "mentiras piedosas" sobre o estado do paciente, e tantas vezes pactuadas pelos profissionais que o assistem (ANCP, 2009).

Pacheco et al. (2020) realizaram uma revisão de literatura sobre aspectos da comunicação entre profissionais e pacientes sob cuidados paliativos. Os autores destacaram a escuta, a compreensão da linguagem própria do paciente, bem como os fatores envolvidos na presença ou ausência de discurso, tratando-se também da comunicação não verbal. Há que se considerar o alto impacto emocional gerado no paciente, diante do anúncio de uma má notícia, corriqueiramente associado aos sentimentos de medo, angústias e incertezas.

Para a instituição dos Cuidados Paliativos na oncologia, por exemplo, não é preciso esperar que a doença se encontre avançada, numa fase final. O câncer metastático já se sinaliza como ameaçador à continuidade da vida e, mesmo que o paciente tenha um perfil clínico favorável a tratamentos antiblásticos, recomenda-se o acompanhamento simultâneo com a equipe de Cuidados Paliativos. E quando a doença avança, dando sinais de ineficácia do tratamento antineoplásico dirigido, é importante que o oncologista interrompa a terapêutica oncológica. Seu tratamento será exclusivamente paliativo agora, observando-se o critério de proporcionalidade, reforçando a atenção para a qualidade de sua vida e respeitando o processo 
natural de doença que se impõe (Silva, 2008).

Há um grande abismo que separa médico e paciente (Charon, 2015). Distância densa demais para ser atravessada. De um lado há aquele que sofre em todas as suas camadas; do outro, o que está bem, por vezes, com um olhar reducionista, um profissional técnico. O estímulo a um repertório enriquecido por outros saberes, aguçando sentidos, pode produzir para o futuro médico e para o profissional, uma ampliação do seu olhar sobre a pessoa adoecida (Novis, 2021).

Médicos e equipe que cuidam do paciente oncológico são tocados pelo sofrimento alheio, e incorrem às vezes em equívocos de um distanciamento que "ajudaria" na compreensão da moléstia do outro e na escolha da melhor terapêutica, por não estar envolvido pela sua dor. Mas não existe escudo protetor. Não é necessário, na verdade, até porque é inevitável ser atravessado, tocado pela dor do paciente. E o desvelar do outro a partir de uma escuta ativa às suas histórias de vida pode produzir melhor resultado na relação entre o profissional e o paciente, suas intersecções que podem ajudar no cuidar também de quem cuida (Arantes, 2019).

Os Cuidados Paliativos atentam para o sofrimento além-corpo, a dor total que incorre nesse doente, e também lembra da necessidade do cuidado que o cuidador (incluída aqui a equipe de saúde) deve também buscar para si. Abrir espaço para ouvir/contar histórias dos pacientes, fortalece conexões, produz estreitamento de relações, e facilita a comunicação nos momentos mais difíceis no percurso da doença (ANCP, 2009).

É preocupação dos Cuidados Paliativos a observância das dimensões biopsicossocial do paciente, ponto que se pode entender como inerente ao pensamento médico como um todo, o que, muitas vezes, não se confirma na atuação médica do dia a dia (OMS, 2002).

Encontramos essa preocupação implícita nas Diretrizes Curriculares Nacionais para o curso de Medicina, descrita na Resolução CNE/CES no 3, de 20 de junho de 2014, em que se verifica o apontamento para a necessidade de uma formação médica humanista, reflexiva, crítica, ética e compromissada com a dignidade e a saúde integral do ser humano, mas ao graduando de Medicina, as disciplinas humanistas permeiam sua grade perifericamente, o que de fato é uma pena, por ser indispensável o estímulo a uma formação médica mais humanizada, em tempos de louvação ao tecnicismo e a funcionalidade.

Os cursos de graduação da área da saúde ainda não superaram a influência do modelo biomédico e não conseguiram efetivar o desenvolver de estratégias educacionais que de fato sejam direcionadas à promoção da saúde e à prevenção de doenças, às práticas médicas humanizadas, considerando a biografia do paciente e os saberes populares (Azevedo \& Pelicioni, 2011).

No consultório oncológico, depara-se com a dor total do paciente, sofrimento originado em todas as dimensões biopsicossociais e espirituais, presentes em todo ser humano, e que está aumentado em doenças com um curso que talvez não se possa modificar. Assim é no câncer avançado. Por isso, o conhecimento da paliação se faz imprescindível na atenção às pessoas com neoplasia maligna avançada, iniciando os cuidados paliativos o mais precocemente (OMS, 2002).

Os Cuidados Paliativos buscam promover a qualidade de vida de pacientes e de seus familiares, que enfrentam doenças ameaçadoras à continuidade da vida, por meio da prevenção e do alívio do sofrimento. Para este fim, requer identificação precoce, avaliação e tratamento da dor e de outros problemas de natureza física, psicossocial e espiritual. Evidencia-se a partir desta definição, a necessidade da atuação em equipe interdisciplinar, realizada em âmbito hospitalar, ambulatorial ou domiciliar (Arnauts e Cavalheiri, 2021; OMS, 2002).

Os Cuidados Paliativos, sem dúvida, ajudam a produzir melhores desfechos nas terapêuticas propostas para doenças agressivas como o câncer. E quando se fala melhor desfecho, enfatiza-se o melhor tratamento, o mais acertado. O uso de recursos, como a arte, em especial o teatro para este pesquisador, ampliando e avivando os sentidos e assim auxiliando na compreensão das dimensões do ser humano adoecido, são aliados do paliar. Sentidos mais incitados contribuem à percepção das particularidades identitárias do sujeito sob Cuidados Paliativos, e com isso, pode ajudar a tonificar a relação médico- 
paciente, proporcionando um cuidado ainda mais benéfico ao indivíduo fragilizado (Novis, 2021).

Os Cuidados Paliativos não existem sem interdisciplinaridade. O diálogo e a troca com outras disciplinas é fundamental não só para o melhor desfecho em cada caso, mas também para que se possam explorar os temas e questionamentos trazidos à tona, longe de uma "pedagogia da acomodação, quando, acostumados como proprietários de disciplinas, profissionais planejam suas aulas solitariamente, repetindo uma cantilena que se arrasta por anos" (Ávila, 2011, p. 4).

O presente artigo apoiou-se na visão de Habermas, onde concebe que um indivíduo é responsável pela condução de sua biografia e pode construir novas identidades ao longo de sua existência, motivado por fragmentações e rupturas que conduzem a uma superação, permitindo um novo reconhecimento nas interações sociais das quais faz parte, e também nos conceitos de mesmidade (ser idêntico a si e imutável no tempo) e de ipseidade (identidade pessoal e reflexiva, talhada pela alteridade), tratados por Ricoeur (Paes \& Dellagnelo, 2015).

É sobre a vida que mais falamos quando nos aproximamos da nossa condição finita (Arantes, 2017). É sobre a vida que falamos também quando exercemos artes que nos expressam, como o teatro, por exemplo. Esses instantes de vida possuem matizes próprias, uma qualidade especial que atrai o olhar da plateia e lhe instiga uma inquietação (Brook, 1993).

As peças poéticas, objeto final deste estudo, almejaram explorar a potência do signo pelo filtro da arte, de uma dramaturgia criativa, inspirada nas narrativas de vida. Somando-se a uma prática clínica de qualidade, que não abre mão do melhor saber médico sobre o tratamento de patologias agressivas e modificadoras do curso de vida, como um câncer avançado, a poiesis introduzida a esse cuidar, é trabalhada neste projeto, fomentando relações entre aqueles que cuidam e os que são cuidados calcadas pela empatia, pelo sentido de alteridade robustecido. A arte redimensiona, dilatando a visão sobre os contos de vida. Merleau-Ponty desdobra o segredo da visão na reversibilidade entre vidente e visível na experiência do olhar: o homem que vê é um visível junto ao mundo que ele vê, ou, ver implica a possibilidade de ser visto (Furlan \& Rozestraten, 2005).

O objetivo deste estudo é apresentar peças poéticas fictícias sobre os aspectos mais valiosos da vida de pacientes oncológicos, que estão sob cuidados paliativos, baseadas nas narrativas de vida destes pacientes.

\section{Metodologia}

Trata-se de estudo qualitativo, prospectivo, exploratório, pautado na metodologia das narrativas orais de histórias de vida de pacientes oncológicos, sob cuidados paliativos, proposto e executado a partir dos princípios e fases do método científico, em que se busca (re)soluções a problemas observados na comunidade ou em determinado ambiente/situação, planejados e estabelecidos pelo pesquisador e que prescindem investigação, sendo submetidos às etapas do método científico (Koche, 2011). O estudo foi aprovado pelo Comitê de Ética (Parecer 4.690.649), sendo elaborado e executado de acordo com os preceitos éticos previstos na legislação vigente.

Foram adotados como critérios de inclusão, pacientes de ambos os gêneros, com 14 anos ou mais; portadores de neoplasia maligna, matriculados no ambulatório de Cuidados Paliativos do Centro Oncológico do Complexo Municipal Hospitalar de São Caetano do Sul, no município de São Caetano do Sul; estarem lúcidos, conscientes, orientados no tempo e no espaço; com pontuação pela escala de performance status - ECOG - entre zero e três (Cabral Júnior, 2007); e terem assinado o Termo de Consentimento Livre e Esclarecido (TCLE) e o Termo de autorização do uso de imagem e de voz.

A coleta de dados ocorreu durante as consultas oncológicas do ambulatório. Durante a consulta tradicional, o médico oncologista e também pesquisador do presente estudo, convidava os pacientes a participarem do estudo. Aqueles que concordavam em participar, recebiam os termos de consentimento e após esclarecerem as dúvidas, assinavam-nos. Como parte do ambulatório de Cuidados Paliativos, o médico então realizou a anamnese ampliada, em que foram coletadas as narrativas de 
vida.

O nome, Anamnese Ampliada, foi um termo cunhado pelo autor, para destacar o olhar sobre as subjetividades que constroem a identidade do sujeito (enquanto paciente), a partir de suas impressões e de sua memória afetiva, acessadas na sua oralidade.

Seguindo um modelo de documentário de entrevista participativo (Nichols, 2016), o paciente, como entrevistado, foi convidado a contar uma narrativa de vida ao médico pesquisador. Essa entrevista aconteceu em dois encontros, em dias distintos. E esses encontros foram registrados por escrito na ficha de atendimento do paciente no prontuário do consultório, quando de sua recepção para a anamnese inicial tradicional e exame físico.

No espaço (set) de gravação da narrativa, que ocorreu no anfiteatro do complexo hospitalar em que o paciente foi atendido, realizou-se a captura audiovisual da narrativa de vida (anamnese ampliada), como também registro escrito, no caderno de campo, de observações do entrevistador sobre a fala do participante.

A metodologia para a coleta de narrativas de vida seguiu o roteiro de um documentário de entrevistas participativo, proposto por Nichols (2016). Nesta pesquisa, a fórmula fez com que o entrevistador/pesquisador interagisse com o entrevistado, instigando-o, provocando-o, identificando pontos de virada no seu conto narrado e seguindo uma linha de tempo da memória do paciente entrevistado.

A jornada pessoal do paciente revelada na narrativa colhida não precisou seguir uma linha de eventos encadeados, isto foi falado na explicação, dada pelo pesquisador ao paciente, sobre como aconteceriam os dois encontros.

Temporalidade, singularidade, causalidade ou contingência, intersubjetividade e ética, os cinco pilares da Medicina Narrativa, especialidade criada por Rita Charon (2008), assim como a atenção demandada às dimensões biopsicossocial e espiritual fartamente observadas nos Cuidados Paliativos, no que se referem ao paciente com câncer avançado, foram atentamente observados e constituíram suportes referenciais para a metodologia aplicada à pesquisa.

Não se buscou um estudo da psique, tampouco as peças poéticas exploraram a condição de vulnerabilidade do doente. É sobre a vida que as peças poéticas inspiradas nas narrativas desses pacientes querem falar, e assim estimular a relação médico e paciente, no fortalecimento de um olhar humanizado pelo primeiro.

No segundo encontro, era apresentada ao paciente uma obra de arte escolhida (literária, musical, plástica, performática), inspirada em algum aspecto da narrativa de vida do paciente observada pelo pesquisador. A obra era relacionada a algum elemento simbólico ou significativo notado na primeira entrevista. O paciente foi, então, convidado a expressar, de maneira livre, sobre o efeito que a obra apresentada lhe causou. Poderia ser uma frase, uma palavra, um comentário etc. Os encontros eram por fim encerrados. Esse registro se tornou elemento na inspiração da peça poética a ser escrita e produzida.

As narrativas de vida coletadas, transmutadas ao fim em peças poéticas, foram registradas no prontuário do paciente participante desse ambulatório. Vale ressaltar que o processo para a criação das peças poéticas seguiu um roteiro que passou pela análise do material colhido nos registros de áudio e vídeo, depois transcrito e, por fim, reescrito como uma peça poética.

\section{Resultados e Discussão}

Neste estudo, valorizou-se a investigação de elementos da memória afetiva de pacientes com câncer, sob cuidados paliativos, e que moldam a sua identidade. O problema que se adequa ao projeto são histórias de vida narradas que se mostram necessárias para iluminar as relações significativas que o entrevistado (narrador) estabelece em sua jornada de vida anterior ao câncer.

Optou-se neste manuscrito, pela apresentação de duas narrativas de vida de pacientes com câncer, transmutadas para peças poéticas. Nos encontros para as coletas das narrativas, o pesquisador já revelou o espírito colaborativo na coleta das histórias, e como as relações entre narrador e pesquisador ganharam novos contornos. Adotou-se nomes fictícios para todos os 
atores envolvidos, visando à preservação da identidade e privacidade dos participantes, ainda que os mesmos tenham consentido por escrito a divulgação dos dados, respeitando-se os preceitos éticos da legislação vigente.

As imagens evocadas nas histórias narradas ganham destaque pelo pesquisador. Para isso, o pesquisador busca estabelecer relações de elementos da fala do entrevistado que denotam sua personalidade, humor e temperamento.

\section{Hellen: a dança}

Internada no hospital municipal, Hellen aguarda a remoção de um sarcoma de partes moles que cresceu em cerca de um ano em sua coxa esquerda. O médico (e também pesquisador) é chamado às vésperas pelas equipes de cirurgia geral e vascular para a avaliação oncológica, uma vez que os exames de imagens denotaram uma proximidade do tumor de vasos importantes da sua perna, aumentando o risco de amputação durante o procedimento. Ela está a poucas semanas de completar 19 anos.

Nesta primeira visita, sua companheira de quarto é uma prima de 17 anos. Tímida, não fez perguntas durante a avaliação. Seu quadro clínico geral é muito bom, com o destaque para a extensa lesão na raiz de sua coxa esquerda. O tumor exteriorizou-se numa ferida aberta, após um choque na parede do seu quarto, em sua casa. Inflamou e infectou, o que motivou a sua internação e a realização dos exames para a confirmação do diagnóstico. Já com a infecção debelada, a cirurgia foi por fim agendada.

Hellen está ansiosa para se ver livre do tumor, mas a avaliação médica frustra sua expectativa, pois confirma-se alto risco de amputação. Um tratamento quimioterápico prévio foi indicado para a redução da lesão.

Chama a atenção do médico, o longo tempo para a definição diagnóstica. É sabido que sarcomas de partes moles têm crescimento lento no início, insidioso até, quase não produzindo sintomas significativos. A localização em sua perna pode ter confundido com algum nódulo benigno inicialmente, e ter sido pouco valorizada.

Claro que um olhar mais treinado e pensar sobre lesões agressivas favorecem a investigação, acelerando o seu diagnóstico. Que outras questões poderiam fazer com que a paciente escondesse o tumor? Este não é um comportamento incomum. Por vezes, recebe-se pacientes adultos que não procuram o atendimento profissional quando já exibem sintomas significativos de uma doença maligna, ou mesmo quando detectam uma tumoração que cresce às vistas, com aspecto suspeito, e que, por motivos individuais, esses pacientes preferem não procurar ajuda.

Algo dificultou o diagnóstico mais precoce para Hellen. Desde o primeiro atendimento do médico/pesquisador, notara o seu olhar que pedia conexão, atenção, compreensão. Estava assustada. E seu corpo falava, gritava.

Percorrer os exames, avaliar as minúcias do tipo de sarcoma é fundamental para a decisão da melhor proposta terapêutica a ser adotada. $\mathrm{O}$ exame histológico, resultante da biópsia, revela um tipo de Alto Grau. Por ter enorme capacidade para metástases à distância, é preciso ter certeza quanto à sua extensão, que outros sítios podem estar acometidos. Para isto, exames de imagens mais acurados e adequados são realizados. No caso de Hellen, o tumor é localizado, embora seja grande.

Decide-se então pelo tratamento prévio, citorredutor, com quimioterapia, com cirurgia após um mínimo de três ciclos. Foram feitos os preparativos, com implante de cateter central de longa permanência. Ela recebeu alta para concluir a antibioticoterapia em sua casa, e uma semana após, iniciaria a quimioterapia em regime internado.

É preciso uma atenção redobrada ao impacto emocional em situações como a de Hellen. Claro que qualquer diagnóstico de uma doença grave, que promove mudanças significativas na rotina de alguém é impactante. E quando se sabe tratar-se de um câncer, há o temor imediato de que se pode morrer por isso. Ainda assim, algumas situações possuem peculiaridades que saltam de imediato nos primeiros momentos. Câncer na infância e na adolescência tensiona a todos que estão envolvidos: paciente, familiares, amigos e equipe de saúde por motivos óbvios. Há uma comoção inerente.

Hellen vive com a sua mãe, Fabiana, e um irmão menor de cinco anos. Os pais se separaram quando ela ainda tinha 
quatro anos de idade, e não se comunica com o seu pai desde a separação. Tem na prática de sua religião o ponto alto do seu dia, como gosta de repetir. Está muito ansiosa por voltar aos encontros com o grupo de sua igreja.

Embora sempre comedida, de poucas palavras, e ainda com certa timidez, ela procura prestar muita atenção aos esclarecimentos sobre a doença e sobre o tratamento. Quando se confirma o ciclo de quimioterapia, o regime escolhido que contemplava cinco dias seguidos de sessões em internação hospitalar, ela desabou em choro. Aflita, emocionada, passa a questionar o porquê da conduta novamente (NCCN, 2021).

Em todos os casos, o acolhimento é feito por equipe multidisciplinar, e o papel da psicologia é dos mais relevantes, corroborando Arnauts e Cavalheiri (2021). Sempre reforço a mim que preciso aguçar todos os meus sentidos na acolhida dos pacientes. Ouvir, ouvir, ouvir, atentar para toda a fala produzida nas expressões do seu corpo.

Ao pesquisador se volta, neste caso de Hellen, às questões sobre o tempo entre o aparecimento da lesão e o diagnóstico definitivo. O medo em saber do que era esse tumor em crescimento. Por vezes, pegamo-nos conjecturando o que as moléstias realmente representam nas suas manifestações em nossos corpos, porque se dão desse ou daquele modo.

É claro que hoje, as respostas das causas são obtidas a partir de uma lógica biológica, das relações do ser humano com o ambiente. Mas esse olhar aponta apenas para alguns aspectos das origens das moléstias. Sim, há registros em nossos corpos que recebemos da nossa ancestralidade, e temos também a nossa singularidade que produz em nós a nossa identidade a partir desses registros. As moléstias que nos acometem serão sempre singulares na sua apresentação em cada corpo humano. Em Hellen, esse sarcoma resulta apenas da sua genética, da sua hereditariedade? Ou seu corpo nos fala algo que precisamos atentar?

Imediatamente à véspera da internação para o início do primeiro ciclo, Hellen tem forte crise de choro e precisa conversar mais uma vez com o médico. Uma consulta é agendada no dia seguinte, e novamente repassam-se os detalhes do tratamento, a necessidade premente de se seguir a proposta escolhida, reforçando o intento que se quer.

É preciso que esse regime seja internado, pelo tempo de infusão das drogas, a observação frequente dos efeitos adversos facilitada com o monitoramento intra-hospitalar. A paciente é lembrada de que o serviço não dispõe de hospital dia. É tudo novo para ela e está muito triste por saber que o seu cabelo cairá. Seus longos cabelos negros são motivo de imensa satisfação para ela. Faz questão de explicar ao médico, o quanto a ideia de perdê-los, mesmo que seja só durante o seu tratamento, lhe causa intenso pesar.

Entende que o tumor está grande, sente-se convencida sobre os riscos que a cirurgia nesse momento traz. Hellen, na verdade, a despeito da imaturidade esperada em seu tempo de vida, demonstra sim preocupação com tudo o que se refere aos cuidados com o seu corpo. Faz questionamentos (ainda que poucos, de início) pertinentes a respeito da doença, dos exames e do tratamento a que se submeterá.

A angústia pela perda anunciada dos cabelos, comum a quase todos os pacientes que passam por um tratamento oncológico, enuncia nosso cuidado com a imagem, como nos vemos, como queremos ser vistos. Em uma época em que a maioria de nós se faz exposto e evidencia quase o tempo inteiro do seu dia, e onde os meios que hoje mediam as relações cobram uma imagem com atributos que seduzem o interesse dos outros, uma fácies jovem, sem cabelos, que remete a um adoecimento, pode provocar perda às conexões que se quer, onde se pretende estar ou já está inserida. Hellen faz parte desse mundo que se comunica bastante através da sua imagem.

Um esquema com medicamentos que quebram o ciclo celular, com doses elevadas, cujos efeitos adversos como náuseas, mal estar abdominal, fadiga são comuns, é difícil de ser enfrentado. A oncologia hoje tem um arsenal de drogas adjuvantes que minimizam muito esses efeitos, mesmo o que o pesquisador considera mais preocupante, que é a queda de imunidade. E isso é preciso sempre relembrar ao paciente e aos seus cuidadores, pois uma neutropenia (queda do número de glóbulos brancos) expõe o paciente a risco infeccioso (NCCN, 2021). 
Hellen tolera bem a maioria dos eventos adversos. A queda do cabelo acontece e, como esperado, produz oscilações no seu humor. Ela tem recebido o suporte da psicologia, o que tem lhe ajudado. Os ciclos vão se sucedendo, e o tratamento segue nos intervalos preconizados. Pouco antes de iniciar o terceiro ciclo do esquema, Hellen é convidada a participar da coleta de sua narrativa de vida. Combina-se o encontro no auditório do hospital.

Nesta primeira entrevista, além do pesquisador/médico e da paciente, há a participação de uma estudante de psicologia. Repete-se o ar de interrogação que percebo no primeiro dia de narrativa de cada paciente. Mesmo com toda a explanação sobre o objetivo da proposta, o modo como se dará, é tudo muito novo. Enquanto pacientes, tem-se a ideia cristalizada de uma consulta médica, seguindo o ritual de uma anamnese tradicional, com a enquete de perguntas que fazemos.

O início talvez lembre a alguns um processo terapêutico, até que se dão conta que estão ali como contadores de história. E é a sua história que será ouvida por nós. Hellen retrai-se de início, mas fala sobre isso, inclusive. Reconhece a sua timidez, e isso é um ponto que considero positivo nessa abordagem. Perceber a sua dificuldade de produzir fala, compartilhar suas memórias, suas reflexões, anseios etc., ajuda para que cavouquemos mais as suas camadas.

"Sempre que assisto um vídeo de dança, de ballet, em minha cabeça, eu danço também. Amo a dança. Me emociona assistir, choro de ver. Choro."

Um longo prólogo foi a primeira coleta de narrativas de Hellen. Foi preciso, com cuidado, instigar para que sua fala viesse, para que se sentisse à vontade. Proponho um resgate de instantes marcantes da sua infância, das brincadeiras que se lembrava, das amizades. Os nomes são importantes.

É possível notar muitas vezes que o seu pensamento está embevecido pela sua fé, pela sua religião. Apenas quando fala da dança que vem à tona uma paixão, uma relação que escapa do dogmatismo.

A seguir, um recorte da peça poética, produzida pelo pesquisador, a partir da narrativa de vida de Hellen.

\section{A dança}

E se deslizo solta no lago? Estou em mim quando danço, e bailo e nem penso. É assim, sabe? Um louvor. Sou garça, sou cisne, sou as próprias asas que me suspendem no ar. Eu posso voar? Quem disse que não? O que me impede de querer, de gritar, da fazer?

\section{- Vai, sua vez! Vai!}

Tá cheio de pedrinhas, e outras pedras, e umas coisas jogadas nesse caminho.

É torto, esburacado às vezes, e você tem quer correr, e tentar adivinhar quando vai precisar diminuir o passo, dar um salto, parar. Você precisa ter essa noção. Nem todo o tempo, nem todo o tempo mesmo, presta a atenção, vai ter onde se segurar. Escuta bem.

\section{- É sua vez, vai!}

Ela olha para os próprios pés, tira as sapatilhas, gira o corpo numa pirueta e para. Fica assim um tempo, num silêncio. Sua prima que já está do outro lado, na grama verde, com vareta fincada, agita os braços, pedindo que ela cruze o caminho. Ela, ainda estática na pirueta congelada, pensa: na minha cabeça, eu danço.

- Ana, eu estou com medo.

Ana, lá longe, do outro lado, na grama verde, com a vareta fincada, gesticula. Outros meninos, zombam, fazem caretas, correm leves no caminho que agora está limpo, liso, sem pedras, sem buracos, ela vê, tem um leve impulso que quase a desequilibra, mas recua, chora e pensa: na minha cabeça...

- Tonta, vem! Assim não dá, tá ouvindo? Não dá não!

- Hei, Ana! Hei!

- Vamos prum outro jogo. Esse acabou. Acabou. 
Desmonta. Desfaz. Desaba. Cai.

\section{Fabiana: Kathmandu}

Fabiana tem um câncer de mama localizado, com um nódulo medindo um pouco mais de quatro centímetros ao diagnóstico. Ela tem 45 anos hoje. Fora encaminhada para receber um tratamento prévio com quimioterapia. Nessas situações, procura-se reduzir primeiro o tumor, possibilitando-se uma cirurgia mais conservadora e segura.

Casos como o de Fabiana ilustram bem a atenção que é preciso dar ao acolhimento na primeira consulta. O tumor localizado em sua mama tem o tamanho, a invasividade e agressividade da sua própria condição biológica, no entanto, esse mesmo tumor, a partir do ponto de vista de Fabiana, tem a potência que ela lhe atribui.

O verbo acolher diz muito em seu significado. E verbo é ação. Parece tão óbvio o seu entendimento. Parece.

Recebemos, acolhemos, nos dedicamos em tempo e presença àquela pessoa que nos escolhe, nos procura para que dela cuidemos. Ações que se fazem necessárias e se pedem sinceras em toda a atenção dos Cuidados Paliativos.

Fabiana é inteligente, esclarecida e com uma fala muito articulada. Fala esta que nunca exibe grandes rompantes, e sempre demonstra uma forte sensibilidade. Desde a sua primeira consulta faz questão de procurar entender tudo o que se refere ao seu câncer, muito atenta às particularidades da patologia, buscando informações em fontes confiáveis frequentemente, e receptiva às orientações sobre o tratamento. Deixa claro sempre que quer estar ativa, produtiva durante o seu tratamento. E esse é um traço muito comum à maioria dos pacientes em tratamento de câncer. É possível que esta seja uma característica humana quando somos lembrados da nossa mortalidade, da nossa finitude.

Casada com Thiago, um músico, com uma filha de 15 anos, Ágata, Fabiana é uma mulher do seu tempo. É protagonista de sua vida, suas atitudes, gestos, fala, estão sempre reforçando a sua consciência disso. Seus afetos, sua família coadunam com seu modo de ser.

Há um cuidado da imagem. Seu figurino busca sempre reafirmar uma alegria de estar, de viver. Cores com vida, vibrantes, são escolhas comuns no seu look. Esse cuidado com a própria imagem parece estar presente em todos os seus momentos. E como as consultas oncológicas e os dias de quimioterapia passam a fazer parte da sua rotina, recebem cores e cuidados. Para ela, é preciso lembrar que são instantes da sua vida também. Ela nunca se esconde.

Nos intervalos dos ciclos da quimioterapia escolhida (NCCN, 2021), Fabiana é um misto de medo e esperança. Como é preciso a checagem de hemograma e bioquímica nesses hiatos, para aferir a repercussão do tratamento na medula, esses poucos minutos da análise são de uma espera angustiante para o paciente, mesmo que esses exames não sejam para avaliar a resposta do tratamento.

Poucas semanas após o primeiro ciclo, o nódulo em sua mama reduziu bastante, motivo de muita emoção para ela. Ainda assim, a queda na imunidade no nadir de cada sessão lhe causava muita tensão. Só aliviada a cada consulta, com as explicações do médico. Esse medo é comum. É preciso da parte do médico, compreensão. Repetir o que já foi dito sobre a repercussão do tratamento é sempre necessário. O paciente costuma associar qualquer alteração nos exames que não estejam dentro dos parâmetros de normalidade habituais como sinal de piora do quadro de doença.

Há uma história a reboque de cada moléstia. O olhar, a respiração, os gestos, as nuances da fala de Fabiana, desde que apontou na porta do consultório no primeiro atendimento, queriam me contar dela. Sua fácies é reveladora. Ser jornalista com uma preocupação de refletir sobre o mundo, de se engajar nas questões sociais escapa frequentemente na sua fala. Quero saber, dialogar, refletir junto. Sinto que ampliar a minha escuta ajuda na acolhida, no cuidar. Ela gosta de falar, de demonstrar o seu sentimento sobre as coisas, sobre as pessoas, sobre aquilo que faz e acredita. Sua voz, expressões, gestos às vezes estão em sintonia com os sentimentos, outras não.

Cabelo em queda profusa, náuseas, são os sintomas comuns ao regime quimioterápico prescrito para ela. E Fabiana 
tem boa tolerância. Convive apenas com a neutropenia, queda do número de glóbulos brancos.

- Essa quimio é a vermelha, doutor?

Pergunta recorrente no consultório de oncologia às primeiras consultas. A cor vermelha está associada a um quimioterápico usado há muito tempo, que provoca queda de cabelo e muita náusea. Hoje são tantos os medicamentos quimioterápicos, além de uma gama de outros para os efeitos adversos, que essa associação da cor vermelha com intensidade e/ou má tolerância perdeu o sentido. Mas considero sempre importante esclarecer esse ponto a cada paciente.

A seguir, apresenta-se recorte da peça poética produzida a partir da narrativa de vida de Fabiana.

\section{Kathmandu}

- Quando foi mesmo? Era cedo? Eu vou rir, muito. Adivinhou por quê?

- Tarde da noite, Bia! Que mania é essa agora?

A menina respirou fundo e coçou o nariz. Viu que a sombra do pai sumiu junto com a luz do corredor que apagou. Seu pai deixava a porta do seu quarto em fresta. Ela não queria se sentir sozinha. Sentia falta da mãe todo dia, o dia todo, nos seus seis anos achava que crescia depressa, mais depressa que qualquer um. Bem mais depressa.

- Bia! Bia! Te achei! Te achei!

Nicinha ria marota e lhe apertava num abraço doido, toda vez que se encontravam. Era o mesmo Sol e sempre na sobreira do vô Valdir. Sempre.

- Que coisa! Desaperta, Nicinha! Ai!

Nicinha cai no riso.

- Você sabe a distância até Kathmandu?

- É longe. Bem longe.

- Vô Valdir falou que o buraco que a gente cavou na oficina...

- Não chega até lá!

- Nicinha...

- Não chega! É longe esse lugar. Eu sei que é! Tem de dar uma volta muuuito redonda e cheia de subidas e mais outras voltas e a gente pode cair.

Nicinha fala dando piruetas.

- Vô disse que o buraco vai dar noutro lugar.

- Que outro?

Bia olha pro chão, entre os pés e só aponta pra baixo com o dedo indicador esquerdo. Nicinha acompanha e arregala os olhos. Depois aperta Bia noutro abraço, e aperta os olhos. Ela treme. Bia fala baixinho.

- Ele tapou o buraco e pôs o baú em cima. Disse pra gente não cavar mais.

Nicinha afrouxa os braços. Olha no olho de Bia.

- A gente vai pra Kathmandu. Mas vamos de barco, tá?

- Tá.

A Medicina Narrativa introjetada aos Cuidados Paliativos de pacientes oncológicos não substitui nada do que essa prática clínica faz, mas esta será fortalecida pela compreensão das consequências que têm as narrativas de vida coletadas dos pacientes, guiadas por aquele referencial teórico (Charon, 2008).

A clínica, soberana no fazer médico, pode ter mais um domínio aliado. Que não é necessariamente novo, soando como um resgate de uma atuação que sempre foi parte da prática médica. O corpo biográfico quer partilhar sua história. As 
histórias de vida estão ali para que as ocupemos também e sejamos por elas atravessadas. Sim, iremos nos comover e não precisamos esquecer disso (Charon, 2016).

Histórias reais são o tempo todo ficcionadas na arte. O teatro é a arte mais humana, cuja ferramenta é o corpo do ator, e seu acontecimento se pauta pela efemeridade, pelo instante de conexão entre atores e plateia que nunca será repetido. Teatro é uma prática humana que permite "condensar a vida" no palco (Brook, 1993).

Essa vida no palco tem pulso, cor e vigor constantes e de enorme interesse. Essa vida nos quer tocar, atravessar, nos fazer pensar, refletir, aprender. Vida que acontece também nas relações, nas conexões. E a arte media conexões e joga luz nas fronteiras onde elas acontecem (Brook, 1993; Charon, 2015).

Prestar atenção às zonas de fronteira entre um espaço e os seus vizinhos contíguos-porém-diferentes é uma forma de nos localizarmos nos espaços em que nos encontramos. Uma vez localizados, podemos identificar com maior habilidade o que estamos fazendo, quem somos e, às vezes, até mesmo o que tudo isso pode significar. (Charon, 2015).

A esta pesquisa importou a fabulação poética a partir das narrativas de vida, não para explorar a dor, a moléstia pelo qual passa o paciente, mas saber do sujeito através dos seus afetos identitários, que iluminam suas várias dimensões em suas ambiguidades. A história de vida de cada um não segue cartilha ou catalogação científica. Não há um trajeto único, tampouco respostas absolutas à sua compreensão (Manguel, 2007).

Aqui também vale ressaltar o olhar estendido que vai além de saberes cristalizados, buscando incentivar a obtenção de repertório que favoreça uma prática médica mais humanizada. O convite e a procura de outras disciplinas que conversem com a temática e sejam promotoras de saúde foi também objeto deste trabalho. Saberes que avançam além de uma perspectiva mecanicista e biológica do ser humano (Azevedo \& Pelicioni, 2011).

\section{Considerações Finais}

O espaço de fala proporcionado pelo ambulatório de Anamnese Ampliada, com a demanda de tempo mais dilatada para a produção de maior interação entre equipe de saúde participante e o paciente, traz um acolhimento diferenciado. O paciente está mais presente, mais preenchido de si. Nota-se maior relaxamento e produção de falas mais espontâneas quando não há como pano de fundo uma consulta médica tradicional.

Ser e estar como um contador de história (da sua história) que não tenha sua doença como mote e, também, não se tratando de uma análise de sua psiquê, além de ter uma atenção genuína da equipe, estreita ainda mais os laços em nossa percepção. Iniciar uma conversa sobre a progressão, sobre a finitude que se avizinha torna-se mais acessível.

As peças poéticas, na procura da amplificação dos signos contidos nas narrativas colhidas, querem conduzir o olhar do espectador para a necessidade que temos de sempre enxergar o sujeito através de suas camadas, de aguçarmos todos os sentidos em nosso ato de cuidar do outro.

Novos estudos podem ser propostos visando analisar os efeitos da utilização das peças poéticas nas atividades pedagógicas dos cursos de ensino superior em saúde, considerando os preceitos das metodologias ativas, inclusive no ensino das práticas de saúde, no internato médico, residência médica e multiprofissional, estágios supervisionados e outras práticas de educação permanente.

\section{Referências}

Academia Nacional de Cuidados Paliativos [ANCP], (2009). Manual de cuidados paliativos. Diagraphic,

Arantes, A. A. Q. (2019). A morte é um dia que vale a pena viver-e um excelente motivo para se buscar um novo olhar para a vida. Editora Sextante.

Arnauts, D. B., Cavalheiri, J. C. (2021). Perception of nurses in palliative care assistance. Research, Society and Development, 10: (1), e5710111088, 10.33448/rsd-v10i1.11088. 
Research, Society and Development, v. 10, n. 11, e583101119919, 2021

(CC BY 4.0) | ISSN 2525-3409 | DOI: http://dx.doi.org/10.33448/rsd-v10i11.19919

Ávila, L. A. (2012). O corpo, a subjetividade e a psicossomática. Tempo psicanalitico, 44(1), 51-69. http://pepsic.bvsalud.org/scielo.php?script=sci_ar ttext\&pid=S0101-48382012000100004\&lng=pt\&tlng=pt.

Azevedo, E., \& Pelicioni, M. C. F. (2011). Práticas integrativas e complementares de desafios para a educação. Revista Trabalho, Educação e Saúde (Online), 9(3), 361-378. https://doi.org/10.1590/S1981-77462011000300002.

Brook. P. (1993). A porta aberta. Editora Civilização Brasileira.

Cabral Júnior, B. F. (2007). Escalas de Performance. In: Tabelas, equações, questionários e valores de referência. Sociedade Brasileira de Pneumologia e Tisiologia. http://itarget.com.br/newclients/sbpt.org.br/2011/downloads/temp/ESCALAS_DE_PERFORMANCE_DR_CABRAL.pdf.

Charon, R. (2015). O corpo que se conta: por que a medicina e as histórias precisam uma da outra. Editora Letra e Voz.

Charon, R. (2008). Narrative Medicine: Honoring the Stories of IIIness, USA: Oxford University Press.

Charon, R. (2016). The Principles and Practice of Narrative Medicine, USA: Oxford University Press.

Furlan, R., \& Rozestraten, A. S. (2005). Arte em Merleau-Ponty. Revista Natureza Humana, 7(1), 59-93. http://pepsic.bvsalud.org/scielo.php?script=sci_artt ext\&pid=S151 7-24302005000200002\&lng=pt\&tlng=pt.

Koche, J. C. (2011). Fundamentos de metodologia científica: teoria da ciência e iniciação à pesquisa. Vozes.

Manguel, A. (2008). A cidade das palavras. Editora Companhia das Letras.

National Comprehensive Cancer Network [NCCN]. (2021). Breast Cancer. (Version 7.2021). www.nccn.org/professionals/physician_gls/pdf/breast.pdf

National Comprehensive Cancer Network [NCCN]. (2021). Soft Tissue Sarcoma (Version 2.2021). https://www.nccn.org/professionals/phy sician_gls/pdf/sarcoma.pdf

Nichols, B. (2016). Introdução ao documentário (6a ed.). Editora Papirus.

Novis, A. L., Geovanini, F., \& Veran, L. (2021). Medicina Narrativa - a arte do encontro. Editora Thieme Revinter.

Pacheco, L. S. P., Santos, G. S., Machado, R., Granadeiro, D. S., Melo, N. G. S., \& Passos, J. P. (2020). The nurse's effective communication process with the patient in palliative care. Research, Society and Development, (8), e747986524.

Paes, K. D., \& Dellagnelo, E. H. L. (2015). O Sujeito na Epistemologia Lacaniana e sua Implicação para os Estudos Organizacionais. Cadernos EBAPE.BR, 13(3), 530-546. https://doi.org/10.1590/1679-395115872.

Resolução CNE/CES No 3, de 20 de junho de 2014 (2014). Institui Diretrizes Curriculares Nacionais do Curso de Graduação em Medicina e dá outras providências. http://www.planalto.gov.br/ccivil/Leis/L9984.htm.

Silva, C. H. D. (2008). Quando o tratamento oncológico pode ser fútil? Do ponto de vista do saber-fazer médico. Revista Brasileira de Cancerologia, 54 (4), 401-410. https://rbc.inca.gov.br/site/arquivos/n_54/v04/pdf/401_410_Quando_o_Tratamento_Oncol\%C3\%B3gico_Pode_Ser_Futil_saber_fazer_medico.pdf

Spence, R. A. J., \& Johnston, P. G. (2001). Oncologia. Editora Guanabara Koogan.

World Health Organization [WHO] (2002). National cancer control programmes: policies and managerial guidelines (2a ed.). 